\title{
FUNCIONAMENTO HÍDRICO E TRANSFERÊNCIA DE MATÉRIA EM UMA VERTENTE NO PLANALTO DE DIAMANTINA - PARQUE ESTADUAL DO BIRIBIRI/MINAS GERAIS
}

\section{FONCTIONNEMENT HYDRIQUE ET LE TRANSFERT DE MATIĖRE DANS UN VERSANT SUR LE DIAMATINA PLATEAU - PARQUE ESTADUAL DO BIRIBIRI/MINAS GERAIS}

\author{
Bruna Fernandes Soares ${ }^{1}$; Guilherme Taitson Bueno ${ }^{2}$; José \\ Alves Ferreira Neto ${ }^{3}$; Everton Sena Santos ${ }^{4}$; Nadia Regina do \\ Nascimento ${ }^{5}$.
}

\section{RESUMO}

O monitoramento da dinâmica hídrica e o estudo geoquímico de elementos dissolvidos em águas subsuperficiais podem fornecer importantes informações para a compreensão da gênese e evolução das coberturas pedológicas de uma paisagem. Assim, o objetivo desta pesquisa é caracterizar estas variáveis em uma vertente representativa do Planalto de Diamantina, localizada no Parque Estadual do Biribiri/MG, mediante o monitoramento do comportamento do nível freático no decorrer de um ano hidrológico com auxílio de piezômetros e mensuração dos teores de elementos químicos (Al, Fe e $\mathrm{Si}$ ) por espectrometria (ICP-OES). Os resultados indicaram que o comportamento do nível freático e os teores dos elementos mobilizados em solução estão diretamente correlacionados aos índices

\footnotetext{
${ }^{1}$ Doutoranda em Geografia - PPGTIE/ PUC Minas brunafernandesgeo@gmail.com

${ }^{2}$ Professor Dr. do Instituto de Estudos Socioambientais (IESA), Universidade Federal de Goiás (UFG) guilhermetaitsonb@gmail.com

${ }_{3}^{3}$ Professor Ms.dos cursos de Engenharia de Minas e Civil da Universidade Presidente Antonio Carlos - UNIPAC Lafaiete jose.neto@unipaclafaiete.edu.br

${ }^{4}$ Professor Ms e coordenador do curso de Licenciatura em Geografia da Faculdade Pedro II senaeverton@gmail.com

${ }^{5}$ Professora Dra - IGCE/UNESP - Rio Claro nascimer@rc.unesp.br
}

Número Especial da Revista Estudos Geográficos - XIII Seminário da Pós-Graduação em Geografia, Rio Claro, 15(0): 80-100, jan./jun. 2017 (ISSN 1678—698X) http://www.periodicos.rc.biblioteca.unesp.br/index.php/estgeo 
de precipitação e aos ciclos de umedecimento/dessecação dos solos, ocasionados pela sazonalidade.

Palavras-chave: Funcionamento Hídrico. Solos. Transferência de matéria. Planalto de Diamantina

\section{RESUMÉ}

La connaissance de la dynamique de l'eau et l'étude géochimique des éléments dissous dans les eaux peuvent fournir des informations importantes pour comprendre la genèse et l'evolution du sol que couvre un paysage. Ainsi, cette recherche vise à caractériser ces variables dans un versant du Plateau de Diamantina - MG, en surveillant le comportement du niveau de la nappe phréatique au cours de l'année hydrologique avec piézomètres et mesure des teneurs en éléments chimiques ( $\mathrm{Al}$, $\mathrm{Fe}$ et $\mathrm{Si}$ ) par spectrométrie (ICP-OES). Les résultats indiquent que le comportement de la nappe phreátique et le contenu d'éléments en solution sont directement corréles au taux de precipitation et aux cycles de humidification/dessèchement du sol causés par la saisonnalité.

Mots-Clés: Dynamique de l'eau. Sols. Transfert de matière. Plateau de Diamantina.

\section{INTRODUÇÃO}

A sazonalidade entre a estação seca e chuvosa, os consideráveis índices de precipitação e as elevadas temperaturas, características em climas tropicais úmidos, condicionam os ciclos de umedecimento e secagem dos solos, os quais tendem a contribuir significativamente para o processo de pedogênese e modelagem do relevo, pois podem intensificar a ação das forças do intemperismo sobre minerais e rochas condicionando, assim, a mobilidade de elementos químicos presentes na rede cristalina dos minerais. No processo de transformação da rocha e das formações superficiais, verifica-se a transferência de matéria e, consequentemente, a redução do volume do material (LUCAS, 1989), que ocorre de forma diferencial nas paisagens.

Duchaufour (2001), afirma que os oxihidróxidos de ferro, alumínio, manganês e silício formam com as argilas uma parte substancial do complexo de alteração, pois os elementos químicos que os constituem podem ser liberados na forma solúvel ou complexados (quando há associação com a matéria orgânica) na rede de drenagem ou se associarem a outros elementos formando, portanto, neominerais como a caulinita e a gibbsita.

A maior ou menor mobilidade destes elementos químicos no pedoambiente está diretamente relacionada a três variáveis: i) disponibilidade de água no meio e 
sensibilidade ao processo redox (GONZÁLEZ-BONORINO, 1972); ii) $\mathrm{pH}$ (BIGARELLA, BECKER; PASSOS, 1994) e iii) agentes bióticos (LUCAS, 2007).

Diante do exposto, pode-se inferir que os estudos da dinâmica hídrica e geoquímica das águas subsuperficiais podem auxiliar nas considerações acerca da gênese e transformações das coberturas pedológicas e modelagem dos relevos. Dessa forma, nosso objetivo pesquisa foi monitorar e caracterizar a dinâmica hídrica e a transferência de matéria em uma vertente representativa do Planalto de Diamantina, localizada no Parque Estadual do Biribiri/MG, mediante o monitoramento do comportamento do nível freático no decorrer de um ano hidrológico, isto é, em resposta às condições determinadas pela alternância da estação chuvosa e seca, e mensuração dos teores de elementos químicos ( $\mathrm{Al}, \mathrm{Fe}$ e $\mathrm{Si}$ ) transportados em solução nas águas subsuperficiais dos diferentes compartimentos pedológicos da vertente investigada.

\section{CARACTERIZAÇÃO DA ÁREA DE ESTUDO}

A vertente investigada localiza-se na superfície cimeira do Planalto de Diamantina (18 ${ }^{\circ} 11^{\prime} 48.2^{\prime \prime} \mathrm{S} / 43^{\circ} 35^{\prime} 52.5^{\prime \prime} \mathrm{W}$ (montante) e 18 $11^{\circ} 57.6^{\prime \prime} \mathrm{S} / 43^{\circ} 35^{\prime} 54.1^{\prime \prime} \mathrm{W}$ (jusante), a $1.427 \mathrm{~m}$ de altitude (topo), na porção $S$ do Parque Estadual do Biribiri (PEB), onde se instalam as cabeceiras de drenagem do Córrego da Roda, em Diamantina - MG (Figura 1).

Número Especial da Revista Estudos Geográficos - XIII Seminário da Pós-Graduação em Geografia, Rio Claro, 15(0): 80-100, jan./jun. 2017 (ISSN 1678—698X) http://www.periodicos.rc.biblioteca.unesp.br/index.php/estgeo 
Figura 1 - Mapa de localização do Parque Estadual do Biribiri, Diamantina MG.

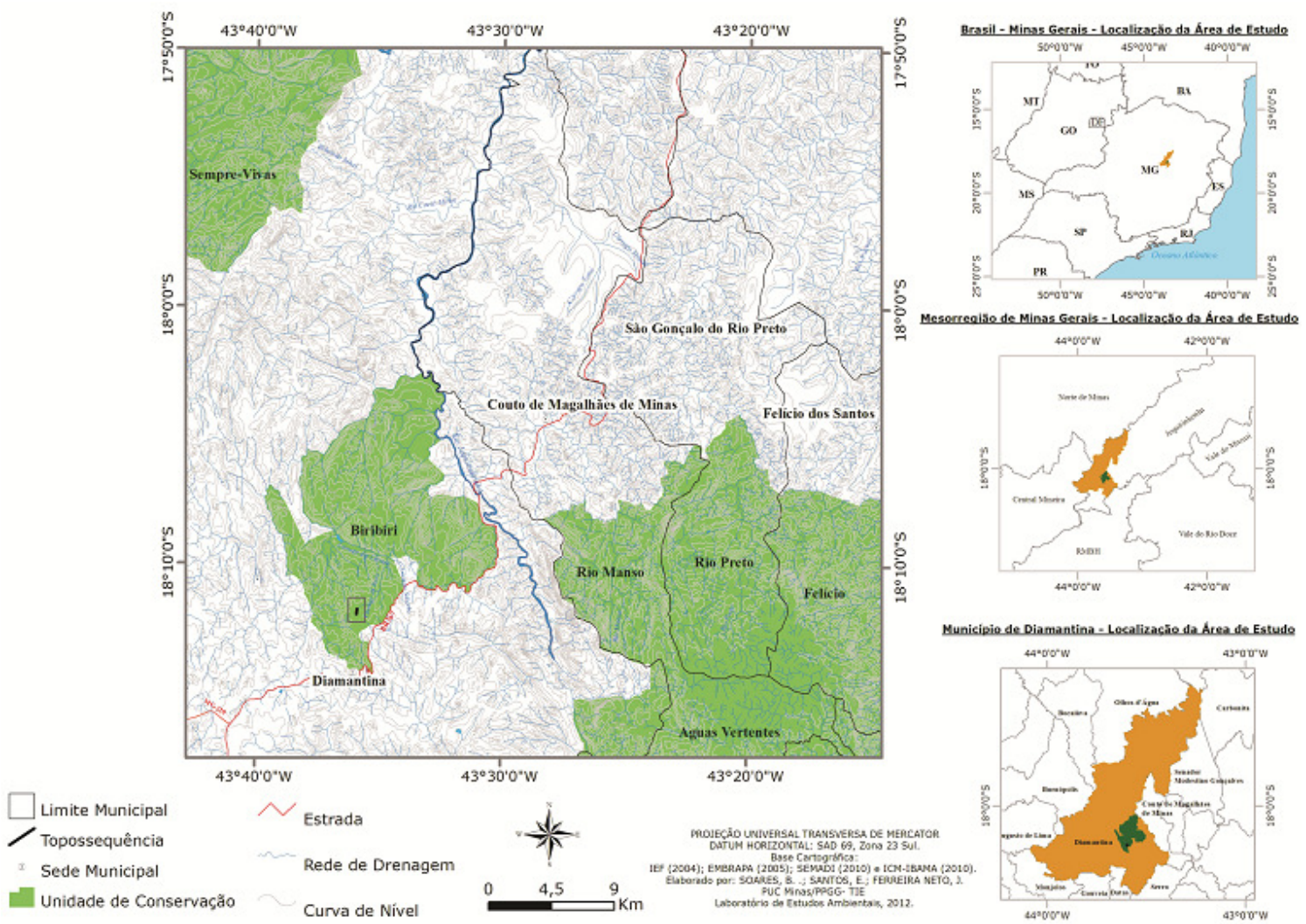

Fonte: SOARES, 2013.

A área de estudo insere-se na porção Centro-Norte da Serra do Espinhaço Meridional. Esta unidade morfo-estrutural, apesar de possuir um relevo bastante acidentado, com níveis diferenciados de dissecação, em cotas altimétricas superiores a $1.000 \mathrm{~m}$ de altitude (NEVE, ABREU e FRAGA, 2005), foi caracterizada por autores como King (1956), Saadi (1995) e Silva et al. (2005) como uma região de planaltos, resultantes da sucessão de eventos desnudacionais e deposicionais que formaram níveis de aplanamento escalonados.

No contexto local, por sua vez, a vertente investigada está situada sobre a Formação Sopa Brumadinho, de origem Proterozóica (RENGER; KANAUER, 1995), cujas rochas predominantes são os metarenitos e quartzitos, com intercalações de metapelitos, xistos verdes, filitos hematíticos e intrusões de rochas metabásicas (ALMEIDA ABREU, RENGER, 2002).

A rede de drenagem apresenta cursos d'água em vales abertos e rasos, que correm sobre superfícies sub-horizontais mais elevadas, formando zonas hidromórficas. A vegetação é de Campo Limpo e os solos dominantes são o CAMBISSOLO Amarelo, - CAMBISSOLO Háplico e o ESPODOSSOLO Ferrihmilúvico (SOARES, 2013).

Número Especial da Revista Estudos Geográficos - XIII Seminário da Pós-Graduação em Geografia, Rio Claro, 15(0): 80-100, jan./jun. 2017 (ISSN 1678—698X) http://www.periodicos.rc.biblioteca.unesp.br/index.php/estgeo 
O clima predominante em Diamantina é o tropical subquente (KÖPPEN, 1931), com duas estações bem definidas, uma seca e outra chuvosa, com precipitação pluvial média mensal de $223 \mathrm{~mm}$ na estação chuvosa e $8,25 \mathrm{~mm}$ na estação seca (total pluviométrico anual médio de $1.404,7 \mathrm{~mm}$ ), e a temperatura média anual é $18,1^{\circ} \mathrm{C}$ (INMET, 2011).

\section{PROCEDIMENTOS METODOLÓGICOS}

O estudo do solo foi feito com base na Análise Estrutural da Cobertura Pedológica (BOULET, 1988). Assim, na vertente foram realizadas 29 tradagens (TC), com o objetivo de identificar as diferenças laterais e verticais dos solos. Após estas sondagens abriram-se 9 trincheiras (TR), onde foram descritas as características morfológicas dos horizontes dos solos, segundo Santos et al. (2005).

O estudo pedológico serviu como base para definir os pontos para a implantação de estações para o monitoramento da dinâmica hídrica e amostragem de água na vertente. Desta forma, foram instaladas quatro estações de monitoramento do nível freático por piezometria ao longo da vertente e cinco coletores de água para análise dos elementos químicos em solução (Al, Fe e Si). As Estações de monitoramento foram denominadas: i) Estação A, localizada junto à TR8, onde foram instalados o piezômetro PA-382 ${ }^{6}$ e os coletores GA-201 e GA-375; ii) Estação B, situada junto à TR5, onde foram instalados o piezômetro PB-380 e a garrafa coletora GB-299; iii) Estação C, situada junto à TR6, onde foram instalados o piezômetro PC-272 e o coletor GC-196; e iv) Estação D, localizada junto à TR7, onde foram instalados o piezômetro PD-97 e o coletor GD-66 (Figura 2).

\footnotetext{
${ }^{6}$ As letras $A, B, C$ e D designam as quatro Estações de monitoramento do nível freático e coleta água onde foram instalados os piezômetros $(P)$ e garrafas coletoras de água $(G)$. Os numerais que seguem estas letras indicam a profundidade $(\mathrm{cm})$ na qual os piezômetros e garrafas coletoras de água foram instalados. A sigla GA-375, por exemplo, refere-se à garrafa coletora de água da Estação $A$, instalada a $375 \mathrm{~cm}$ de profundidade.

Número Especial da Revista Estudos Geográficos - XIII Seminário da Pós-Graduação em Geografia, Rio Claro, 15(0): 80-100, jan./jun. 2017 (ISSN 1678—698X) http://www.periodicos.rc.biblioteca.unesp.br/index.php/estgeo
} 
Figura 2 - Croqui representativo da localização dos piezômetros e garrafas coletoras de água na vertente

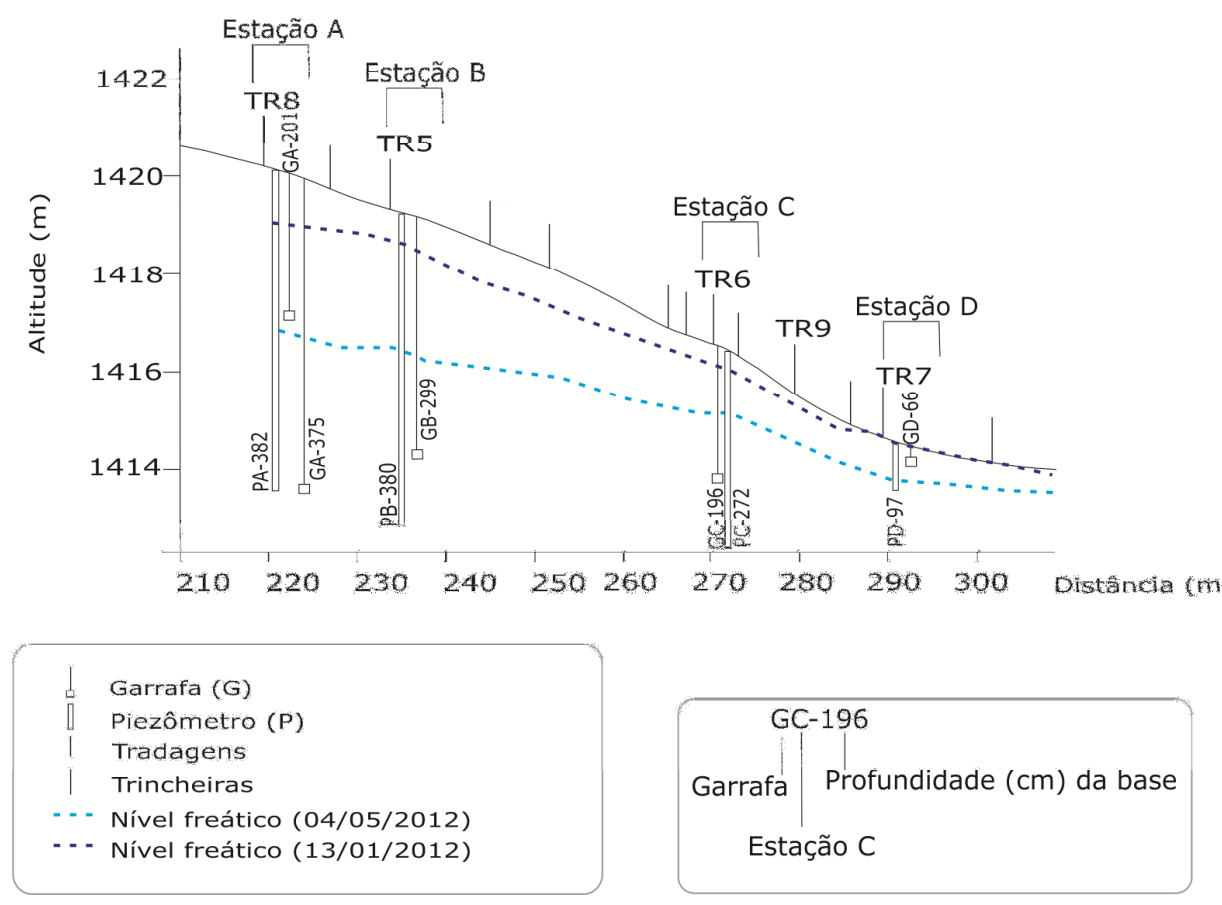

Fonte: Dados da pesquisa

O monitoramento da dinâmica do nível freático por piezometria na vertente ocorreu entre outubro de 2011 e outubro de 2012, mediante leituras semanais do nível freático realizadas, rigorosamente, às $8: 40 \mathrm{~h}$ de Brasília, com o auxílio de uma fita métrica. As amostras de água foram coletadas mensalmente entre novembro de 2011 e setembro de 2012. Estas coletas foram realizadas sempre em triplicata ${ }^{7} \mathrm{com}$ o auxílio de uma bomba de sucção manual e um kitassato.

Após a coleta das águas, mensurava-se seu pH com pHmetro portátil Denver Instrument modelo UP-25, previamente calibrado com soluções tampão de $\mathrm{pH} 4 \mathrm{e}$ $\mathrm{pH}$ 7. Em seguida, as amostras de água eram filtradas através de filtros de membrana de celulose com malha de porosidade igual a $0,22 \mu \mathrm{m}$ e $47 \mathrm{~mm}$ de diâmetro. Finalizados tais procedimentos, as amostras de água eram armazenadas à temperatura de $4^{\circ} \mathrm{C}$ em frascos plásticos de alta densidade, previamente lavados com água destilada e ambientalizados, até serem analisadas no Centro de Energia Nuclear na Agricultura (CENA) da Escola Superior de Agricultura "Luiz de Queiroz" (ESALQ/USP). No laboratório de Ecologia Isotrópica do CENA, os teores de Al, Fe e $\mathrm{Si}$ das águas coletadas na vertente foram determinados por Espectrometria de

\footnotetext{
${ }^{7}$ Embora as coletas de águas subsuperficiais da vertente tenham sido realizadas mensalmente em três dias consecutivos, os dados apresentados nesta pesquisa referem-se à média mensal verificada. Número Especial da Revista Estudos Geográficos - XIII Seminário da Pós-Graduação em Geografia, Rio Claro, 15(0): 80-100, jan./jun. 2017 (ISSN 1678—698X) http://www.periodicos.rc.biblioteca.unesp.br/index.php/estgeo
} 
Emissão com Plasma Indutivamente Acoplado (ICP-OES) no espectrômetro Horiba Jobin Yvon Ultima 2.

Os dados desta pesquisa foram organizados na forma de tabelas e gráficos no software Microsoft Office Excel 2007. Os croquis representativos da vertente, por sua vez, foram desenvolvidos no software CorelDraw X6, no Laboratório de Estudos Ambientais Heinz Charles Kohler, da PUC-Minas.

\section{RESULTADOS}

A vertente investigada (Figura 3) possui $275 \mathrm{~m}$ de comprimento e declividade máxima de $4^{\circ}$. Ela pode ser dividida em três compartimentos: i) alta vertente, do topo a 128 m de distância; ii) média vertente, entre $128 \mathrm{~m}$ a $204 \mathrm{~m}$ de distância do topo; e iii) baixa vertente, de $204 \mathrm{~m}$ até $275 \mathrm{~m}$ de distância. Na alta e na média vertente o substrato litológico é constituído por filito, com intercalações do filito hematítico. Nos 25 metros finais da vertente o quartzito constitui o substrato dos solos, conforme indicado por afloramento situado a $223 \mathrm{~m}$ de distância do topo.

Os solos da vertente podem ser agrupados em dois sistemas maiores de alteração e pedogênese: Laterítico e Hidromórfico. Eles foram subdivididos em: i) Laterítico Pouco Alterado; ii) Laterítico Concrecionado/Plintítico; iii) Laterítico Superficial; iv) Linha de Pedra; v) Hidromórfico Orgânico e vi) Hidromórfico Lessivado (Figura 3). 
Funcionamento hídrico e transferência de...

Figura 3 - Vertente estudada em topossequência no Parque Estadual do Biribiri / MG
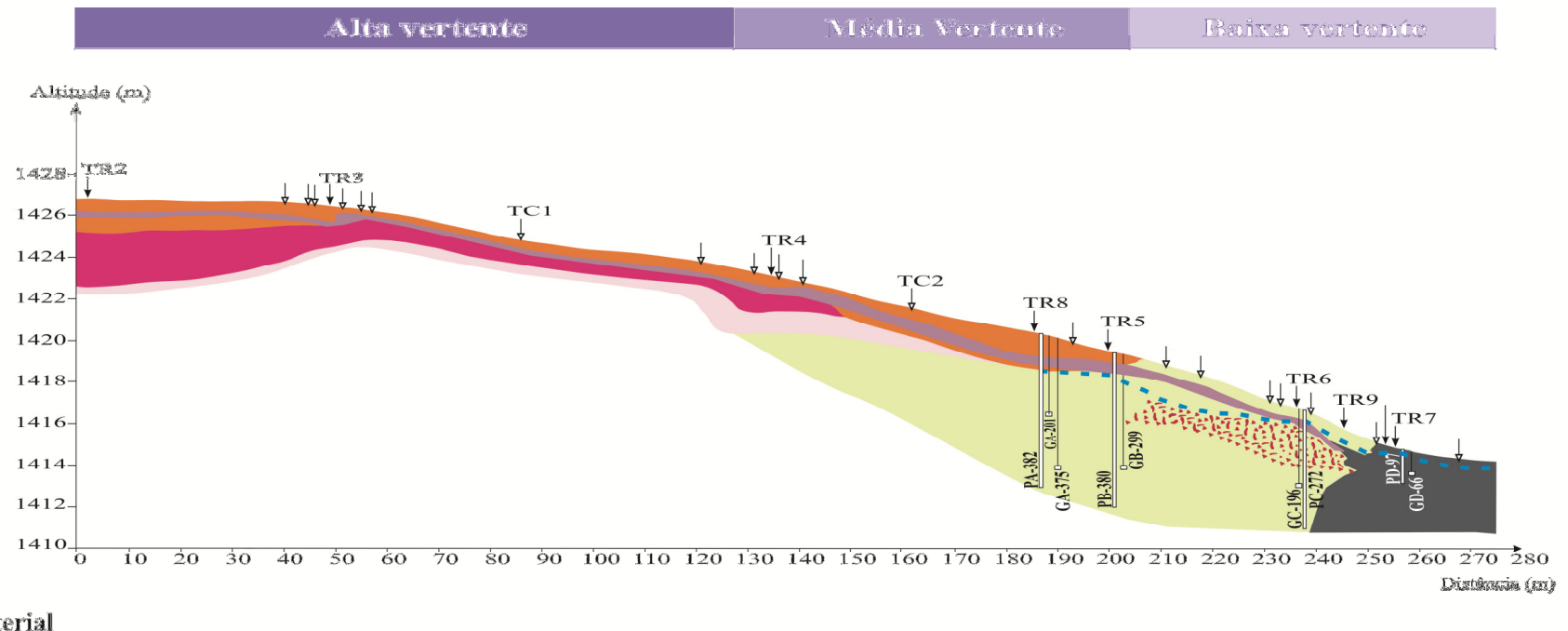

Material

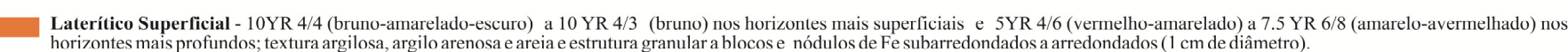

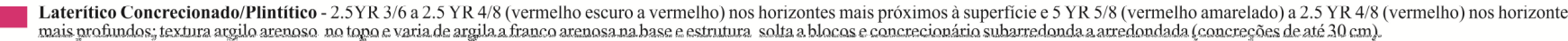

Laterítico Pouco Alterado - 5YR 6/6 (amarelo avermelhado) a 10R 4/8 (vermelho) com mosqueados 10YR 7/6 (amarelo); textura franco argilosa, franco argilo arenosa e franco arenosa e estrutura

Hidromörfico Lessivado- 10 YR 6/8 (amarelo brunado) a 10 YR 4/3 (bruno) nos horizontes superficiaise 10 YR 8/6 (amarelo) a 5 YR $5 / 8$ (amarelo avermelhado) a 2.5 YR 4/8 (vermelho); textura

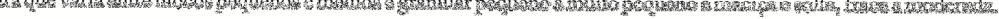

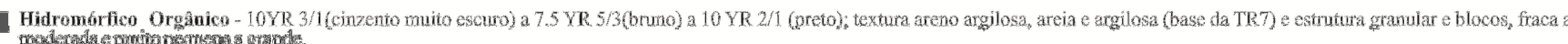

\section{Camada detrifica} Linha de Pedra - material fino com cor varíável entre 5YR $5 / 8$ (vermelho amarelado) a 10YR 5/6 (bruno amarelado) a 7.5YR 5/6 (bruno forte); textura arenosa, franco argilo arenosa e argilo-

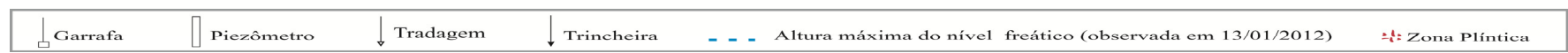

\section{Fonte: dados da pesquisa}

Número Especial da Revista Estudos Geográficos - XIII Seminário da Pós-Graduação em Geografia, Rio Claro, 15(0): 80-100, jan./jun. 2017 (ISSN 1678—698X) http://www.periodicos.rc.biblioteca.unesp.br/index.php/estgeo 
Funcionamento hídrico e transferência de...

O material Laterítico Pouco Alterado agrupa o conjunto de horizontes saprolíticos dos solos, localizado na alta vertente e na parte de montante da média vertente, 0 qual se desenvolveu em um ambiente onde a alteração e a pedogênese dos solos são dominados pelo processo de Laterização, em condições de drenagem livre e oxidação. Os horizontes dos solos constituídos por este material apresentam estrutura laminar herdada da rocha e textura franco argilosa, nas profundidades mais elevadas, transitando para franco argilo arenosa em profundidades intermediárias e franco argilosa no contato com 0 material Laterítico Concrecionado/Plintítico. A cor é heterogênea, variando entre amarelo avermelhado (5YR 6/6) e vermelho (10R 4/8) com mosqueados amarelos (10YR 7/6).

Sobreposto ao material Laterítico Pouco Alterado encontra-se o material Laterítico Concrecionado/Plintítico. Esse tipo de material, tal como o anterior, agrupa os horizontes saprolíticos dos solos do sistema Laterítico, em ambiente oxidante e boas condições de drenagem. A textura dos horizontes dos solos constituídos por esse material é franco arenosa nas áreas próximas ao contato com o material Laterítico Pouco Alterado e argilo arenosa no limite com o material Laterítico Superficial. A estrutura da matriz é solta ou agregada em blocos e verifica-se a ocorrência de material concrecionado subarredondado a arredondado, com até $30 \mathrm{~cm}$ de diâmetro. A cor dos horizontes mais profundos varia de vermelho amarelado (5YR 5/8) a vermelho (2.5YR 4/8) e vermelho a vermelho escuro (2.5YR 4/8 e $2.5 \mathrm{YR} 3 / 6$ ) nos horizontes mais superficiais.

Sobrejacentes aos horizontes constituídos pelo material Laterítico Concrecionado/Plintítico, na alta e média vertente, localizam-se os horizontes formados pelo material Laterítico Superficial. Assim, as cores destes horizontes variam de vermelho amarelado (5YR 4/6) a amarelo avermelhado (7.5YR 6/8) nos horizontes mais profundos e bruno (10YR 4/3) a bruno amarelado escuro (10YR 4/4) nos horizontes mais superficiais. A textura desses horizontes é argilosa no limite com o material Laterítico Concrecionado/Plintítico e, à medida que se aproxima da superfície, torna-se mais arenosa, variando de argilo arenosa a arenosa. A estrutura varia de granular a blocos. Nódulos relictuais subarredondados a arredondados de Fe com até $1 \mathrm{~cm}$ de diâmetro são verificados nos horizontes limítrofes ao material subjacente no compartimento da alta vertente.

O material Laterítico Superficial contém uma linha de pedra, constituída por fragmentos de couraça ferruginosa, nódulos $(1-30 \mathrm{~cm}$ de diâmetro) e seixos de quartzo angulosos a subangulosos ( $2 \mathrm{~cm}$ de diâmetro).

A linha de pedra é contínua e mergulha em direção à jusante acompanhando a topografia da vertente. Na alta vertente, ela possui uma espessura delgada que aumenta gradualmente à medida que se avança para os compartimentos da média e baixa vertente. $\mathrm{Na}$ baixa vertente, todavia, verifica-se que esta camada torna-se cada vez menos espessa até desaparecer no contato com o material Hidromórfico Orgânico.

Número Especial da Revista Estudos Geográficos - XIII Seminário da Pós-Graduação em Geografia, Rio Claro, 15(0): 80-100, jan./jun. 2017 (ISSN 1678-698X) http://www.periodicos.rc.biblioteca.unesp.br/index.php/estgeo 
No compartimento da baixa vertente, o sistema hidromórfico mal drenado e redutor condiciona a gênese de horizontes pedológicos constituídos por materiais Hidromórficos Orgânicos e a instalação de um incipiente processo de podzolização, com a formação de um horizonte Bh (SOARES, 2013).

Os horizontes dos solos formados por material Hidromórfico Orgânico apresentam cores de croma baixa, que variam entre bruno (7.5 YR 5/3) e preto (10YR 2/1), textura areno argilosa e arenosa, com exceção da base da TR7 (Horizonte Bh), cuja textura é argilosa. A estrutura varia de granular a blocos, muito pequeno a grande $\mathrm{e}$ fraca a moderada.

O material Hidromórfico Lessivado, por fim, agrupa os horizontes dos solos formados pela atuação de condições de Hidromorfia temporária, em que se observa a flutuação sazonal do nível freático e a atuação dos processos de redução e oxidação, no período de umedecimento e ressecamento dos solos, respectivamente.

Os horizontes dos solos constituídos por material Hidromórfico Lessivado apresentam cores heterogêneas que variam entre o amarelo e o vermelho (10YR 8/6 e 2.5YR 4/8) nos horizontes de alteração e amarelo brunado (10YR 6/8) e bruno (10YR 4/3) nos horizontes mais superficiais. As classes texturais encontradas neste tipo de material foram classificadas como franco arenosa e areia. A estrutura varia de blocos pequenos e médios a granular pequena a muito pequena, maciça a solta e fraca a moderada.

A figura 4 compara os índices de precipitação registrados pela Estação Meteorológica de Diamantina durante o ano hidrológico de 2011-2012 aos índices da média histórica do clima do município entre nos anos de 1981-2011. 
Figura 4 - Gráfico representativo da média histórica de precipitação $(\mathrm{mm})$ e temperatura máxima e mínima registrada em Diamantina entre 1981-2011 e precipitação do ano hidrológico de 2011-2012

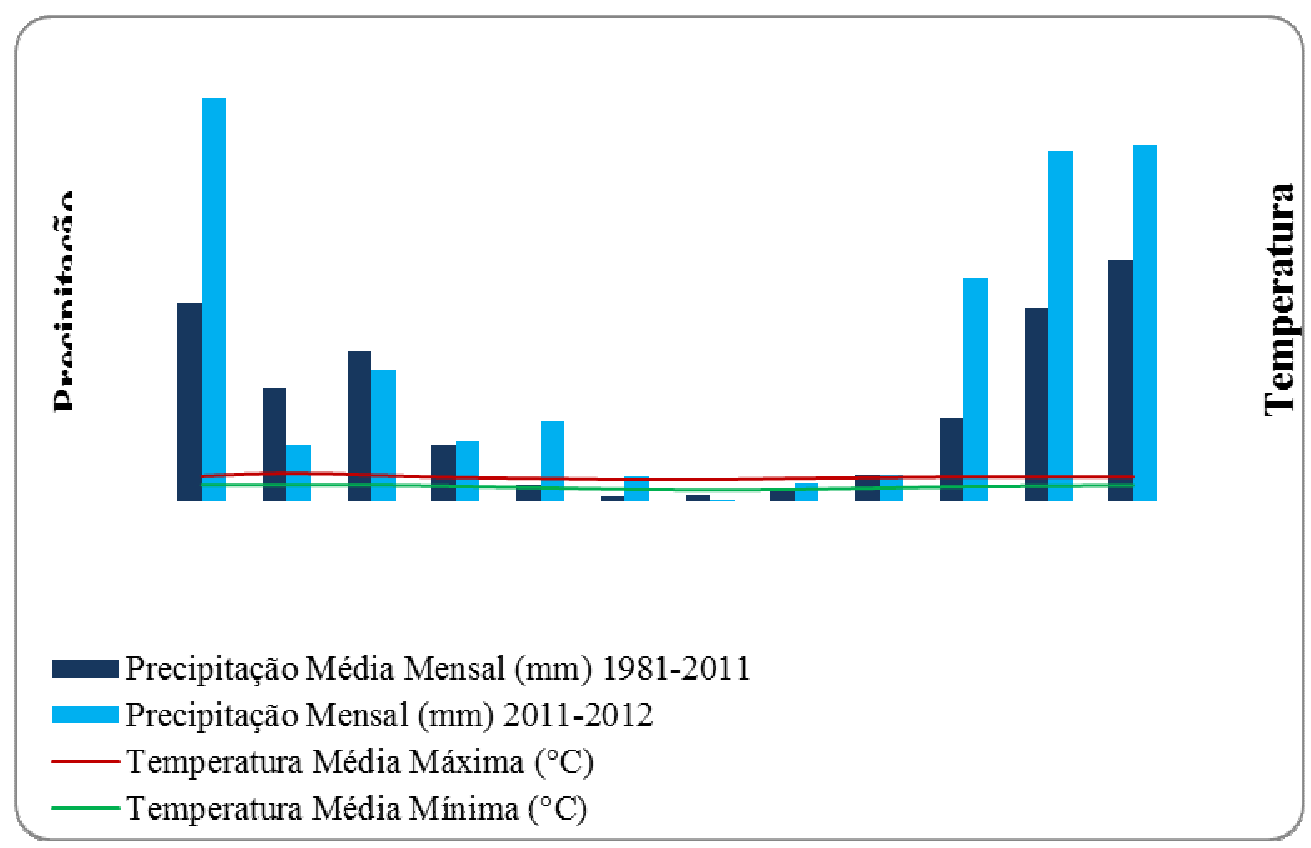

Fonte: INMET, 2011

A precipitação anual acumulada em Diamantina no ano hidrológico de 2011-2012 foi de $1.713,72 \mathrm{~mm}$. Na estação chuvosa, observou-se que a precipitação total acumulada foi igual a $1.644,8 \mathrm{~mm}$, sendo janeiro o mês em que se registrou o maior índice de precipitação $(399,8 \mathrm{~mm})$. Esse índice foi o equivalente ao dobro da precipitação prevista pela média histórica para o mês de janeiro (Figura 4). Nos meses de fevereiro e março, no entanto, os índices pluviométricos registrados no ano hidrológico de 2011-2012 foram inferiores ao da média histórica do município. $\mathrm{Na}$ estação seca, por sua vez, a precipitação total acumulada foi de $68,92 \mathrm{~mm}$. O mês de julho foi o que registrou o menor índice de precipitação $(0,72 \mathrm{~mm})$ e setembro foi o mês em que se observou a maior incidência de chuvas para a estação $(25,8 \mathrm{~mm})$ condicionada, sobretudo, pelos fatores de transição entre as estações.

A figura 5, por sua vez, apresenta a variação do nível freático na vertente estudada em função dos índices de precipitação do ano hidrológico de 2011-2012. Nesta figura é possível verificar que na Estação de monitoramento por piezometria "A", localizada na trincheira TR8 (compartimento da média vertente) (Figura 3), a resposta da elevação do nível freático em relação aos índices de precipitação não foi imediata. 
Figura 5 - Variação do nível freático na vertente em função dos índices de precipitação no ano hidrológico $2011-2012$

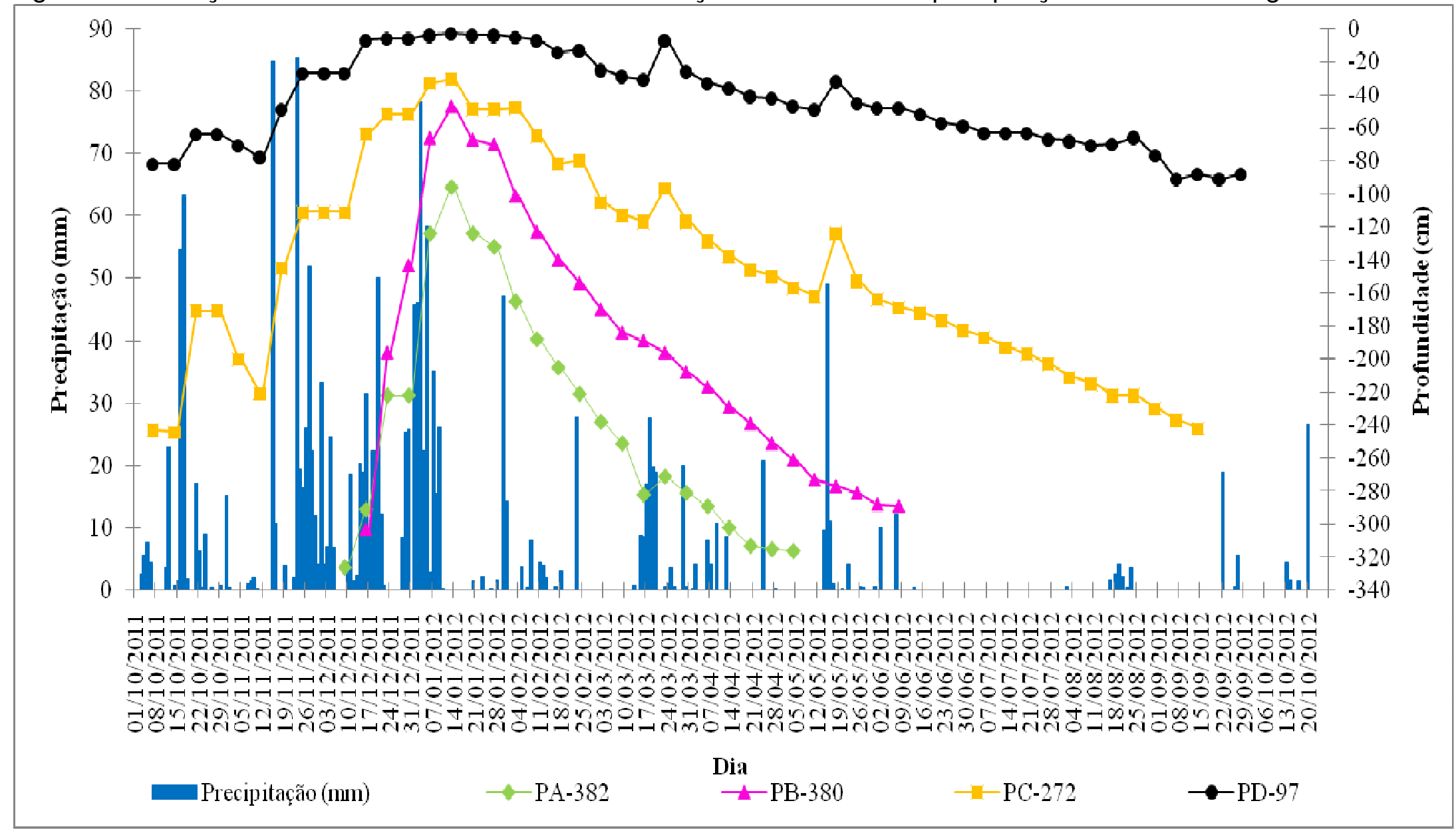

Número Especial da Revista Estudos Geográficos - XIII Seminário da Pós-Graduação em Geografia, Rio Claro, 15(0): 80-100, jan./jun. 2017 (ISSN 1678—698X) http://www.periodicos.rc.biblioteca.unesp.br/index.php/estgeo 
Além disso, verifica-se também na figura 5 que desde o mês de outubro de 2011 foram registrados em Diamantina índices consideráveis de precipitação $(221 \mathrm{~mm}$ de chuva acumulada no mês), entretanto, a elevação do nível freático na vertente somente foi observada a partir de 9 de dezembro de 2011, quando este alcançou a profundidade de $326 \mathrm{~cm}$. A Estação de monitoramento "A" foi a que apresentou a maior amplitude de flutuação do nível freático da vertente $(326 \mathrm{~cm}$ a $96 \mathrm{~cm})$, isto é, o nível freático nesta Estação oscilou entre os horizontes do domínio Hidromórfico Lessivado e a base do material Laterítico Superficial.

Na Estação de monitoramento "B", localizada na trincheira TR5 (compartimento da média vertente) (Figura 3), o comportamento do nível freático, assim como foi verificado no ponto "A", não respondeu imediatamente à variação dos índices de precipitação, sendo necessário, portanto, um maior volume de chuvas para condicionar a elevação do nível freático. Esta elevação começou a ser observada no dia 16 de dezembro de 2011, quando o nível freático alcançou a profundidade de $303 \mathrm{~cm}$ (horizonte constituído por material Hidromórfico Lessivado); a partir desta data até o dia 13 de janeiro de 2012, verificou-se um aumento gradual do nível freático. Em janeiro de 2012, portanto, o nível freático, neste compartimento da vertente, atingiu a profundidade de $47 \mathrm{~cm}$, ou seja, a base do material Laterítico Superficial, o qual constitui os horizontes superficiais do perfil. Todavia, no período compreendido entre 13 de janeiro e 8 de junho de 2012 observou-se que as profundidades alcançadas pelo nível freático neste ponto de monitoramento diminuíram.

$\mathrm{Na}$ Estação de monitoramento "C", localizada na trincheira TR6 (compartimento superior da baixa vertente) (Figura 3), a proximidade com o vale hidromórfico fez com que o nível freático alcançasse profundidades mínimas superiores às verificadas na média vertente, em praticamente todos os meses do ano hidrológico de 2011-2012 (Figura 5). Neste ponto de monitoramento, verificou-se que elevação do nível freático foi imediata após a incidência das primeiras precipitações na estação chuvosa (outubro de 2011, como pode ser observado na figura 5). Contudo, uma elevação mais marcante do nível freático somente foi mensurada após o dia 15/11/2011, quando foi registrada uma precipitação diária de $84,8 \mathrm{~mm}$. Entre esta data e o dia 23/11/2011 foi verificado um período de menor precipitação, que logo influenciou o rebaixamento do nível freático nesse ponto da vertente (Figura 5). 0 período de concentração de chuvas, verificado até janeiro de 2012, proporcionou a rápida elevação do nível freático, dessa forma, a menor profundidade alcançada pelo nível freático na Estação de monitoramento "C" $(31 \mathrm{~cm})$ foi mensurada no dia 13/01/2012. Entretanto, o avanço da estação seca condicionou o rebaixamento do nível freático até $242 \mathrm{~cm}$ de profundidade. A amplitude do nível freático verificada na Estação "C" foi igual a $211 \mathrm{~cm}$.

Nos períodos compreendidos entre 10 e 13 de novembro e 6 e 9 de dezembro de 2011, por exemplo, não foi verificado na área de estudo nenhum evento pluviométrico, consequentemente, as mensurações indicaram um rebaixamento do nível freático nas Estações "C" e "D", durante os períodos citados. No dia 15 de

Número Especial da Revista Estudos Geográficos - XIII Seminário da Pós-Graduação em Geografia, Rio Claro, 15(0): 80-100, jan./jun. 2017 (ISSN 1678-698X) http://www.periodicos.rc.biblioteca.unesp.br/index.php/estgeo 
novembro de 2011, contudo, a precipitação de $84,8 \mathrm{~mm}$ condicionou imediatamente a elevação do nível freático, primeiro na Estação de monitoramento "D" e, em seguida na "C". Este fato foi igualmente verificado nos dias 18 de março e 15 de maio de 2012, quando a incidência de precipitações de $27,6 \mathrm{~mm}$ e 49,2 mm (respectivamente) após um período de estiagem na área de estudo, determinaram a elevação do nível freático nesses pontos de monitoramento (Figura 5).

Os dados do nível freático e da precipitação em Diamantina/MG indicaram que nas Estações de monitoramento "A" e "B" a resposta à variação do nível freático em relação ao aumento da precipitação não foi imediata. Contudo, nas Estações de monitoramento "C" e, principalmente, na Estação "D" esta resposta ocorreu de maneira instantânea, como pode ser verificado nos dias 15/11/2011 (84,8 mm), 18/03/2012 (27,6 mm) e 15/05/2012 (49,2 mm) (Figura 5).

Os dados de $\mathrm{pH}$ mensurados nas águas coletadas mensalmente nas Estações de monitoramento indicaram que na Estação "A" (Figura 2) $0 \mathrm{pH}$ variou de 5,3 (dezembro de 2011) a 6,4 (maio de 2012). Na Estação "B" o valor mínimo para o pH $(5,8)$ foi mensurado em abril de 2012 e o valor máximo do $\mathrm{pH}(7,3)$ em fevereiro de 2012. Na Estação "C", os valores mensurados de $\mathrm{pH}$ variaram entre mínimo de 5,0 (dezembro de 2011) e máximo de 7,1 (agosto de 2012). Na Estação "D" os valores de $\mathrm{pH}$ indicaram mínimo de 4,5 no mês de dezembro de 2011 e o máximo de $(7,4)$ no mês de agosto de 2012. Nesse último ponto de monitoramento foi observada, portanto, a maior amplitude de $\mathrm{pH}$ ao longo do ano.

A figura 6 apresenta os teores de Al, Fe e Si mensurados nas águas subsuperficiais da vertente e a precipitação diária das chuvas registradas em Diamantina - MG ao longo do ano hidrológico de 2011-2012. 
Figura 6 - Gráfico de precipitação diária da chuva e concentração de elementos (Al, $\mathrm{Fe}, \mathrm{Si}$ ) dissolvidos nas águas subsuperficiais da vertente investigada no PEB, Diamantina - MG (2011-2012)
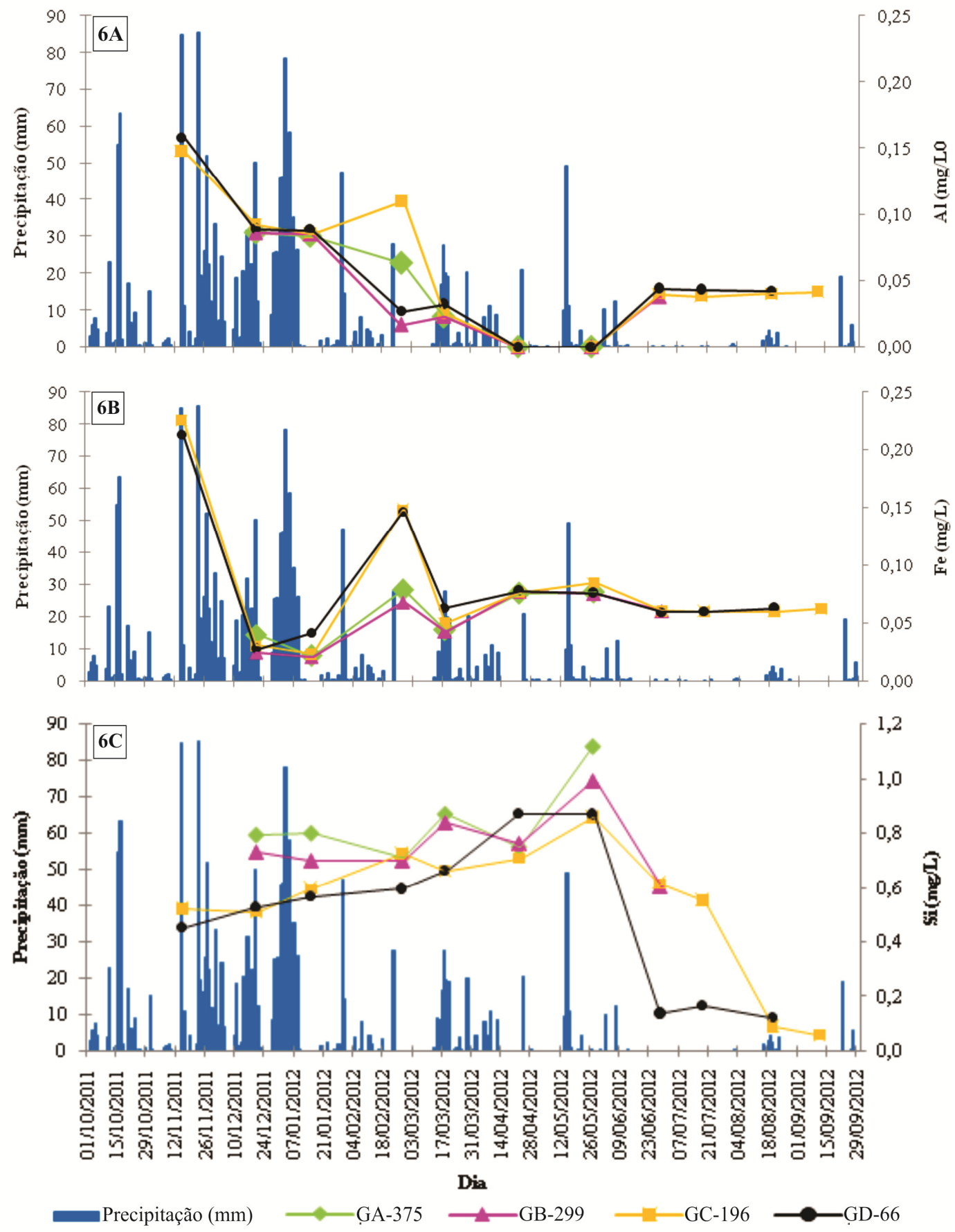

Fonte: Dados da Pesquisa

Número Especial da Revista Estudos Geográficos - XIII Seminário da Pós-Graduação em Geografia, Rio Claro, 15(0): 80-100, jan./jun. 2017 (ISSN 1678—698X) http://www.periodicos.rc.biblioteca.unesp.br/index.php/estgeo 
De acordo com os dados apresentados na figura $6 \mathrm{~A}$, pode-se verificar que a curva para a mobilidade do alumínio, em todas as Estações de monitoramento ao longo do ano hidrológico de 2011-2012 não apresentou (com exceção da coleta realizada em fevereiro de 2012) variações significativas. Percebe-se, assim, que os teores de Al, de modo geral, são diretamente proporcionais aos índices de precipitação, pois durante os primeiros meses da estação chuvosa (novembro a janeiro - precipitação total acumulada próxima de $1.100 \mathrm{~mm}$ ) as concentrações de alumínio foram mais elevadas se comparadas aos teores mensurados durante a estação seca, os quais se aproximaram de $0 \mathrm{mg} / \mathrm{L}$.

Diante do exposto, constata-se que no período no qual ocorreram precipitações diárias superiores a $60 \mathrm{~mm}$, como em novembro de 2011, os teores de Al nas águas subsuperficiais foram superiores a $1,0 \mathrm{mg} / \mathrm{L}$. E, nos períodos em que a precipitação diária foi inferior a $10 \mathrm{~mm}$, como na estação seca, a concentração do Al na água foi próxima de $0 \mathrm{mg} / \mathrm{L}$. A figura $6 \mathrm{~A}$ indica também que no final do mês de janeiro de 2012 a incidência de chuvas em Diamantina - MG começou a diminuir e, consequentemente, o nível freático começou a abaixar (Figura 5). No final de fevereiro, entretanto, ocorreu no dia 27/02 uma precipitação de $27,8 \mathrm{~mm}$ de chuva que influenciou a maior mobilidade do Al nos pontos de monitoramento " $C$ " e "D", respectivamente, mas não interferiu no teor desse elemento nas Estações de monitoramento "A" e "B". Assim, de maneira geral, pode-se afirmar que o alumínio não apresentou ao longo do ano hidrológico de 2011-2012 respostas muito significativas aos eventos de grande precipitação.

$\mathrm{Na}$ figura 6B, observa-se que o Fe apresentou uma considerável sensibilidade à variação dos índices de precipitação, isto é, este elemento teve respostas mais rápidas à elevação ou redução dos índices de mobilidade mediante o comportamento pluviométrico. Os picos mais elevados do Fe foram observados especialmente após os eventos pluviométricos mais intensos, que sucederam sequências de dias sem chuvas. No mês de novembro de 2011, por exemplo, foi registrado o maior índice de precipitação $(84,8 \mathrm{~mm})$ após um evento de estiagem, consequentemente, os teores de Fe mensurados $(0,2254 \mathrm{mg} / \mathrm{L}$ na Estação de monitoramento "C" e 0,2129 mg/L na Estação "D") neste período também foram os maiores registrados durante o ano hidrológico de 2011-2012. Todavia, no período mais chuvoso, como o que ocorreu de novembro de 2011 a janeiro de 2012, verificou-se uma baixa concentração de Fe nas águas coletas.

Os teores de silício ao longo da vertente não apresentaram grandes variações no decorrer da estação úmida (Figura $6 \mathrm{C}$ ). Esses teores aumentaram gradativamente em todas as Estações de monitoramento até o mês de maio. Contudo, na estação seca, a concentração do Si nas águas dos solos reduziu de $1,0 \mathrm{mg} / \mathrm{L}$ para índices próximos de $0 \mathrm{mg} / \mathrm{L}$ nas Estações "C" e "D" (Figura 6C). Ressalta-se, também, que o teor de Si nas águas dos solos, ao longo do ano hidrológico de 2011-2012, não apresentou respostas significativas aos eventos com elevados índices pluviométricos após períodos de estiagem. Assim, a maior mobilidade desse elemento foi verificada somente no final da estação chuvosa (maio de 2012 na

Número Especial da Revista Estudos Geográficos - XIII Seminário da Pós-Graduação em Geografia, Rio Claro, 15(0): 80-100, jan./jun. 2017 (ISSN 1678-698X) http://www.periodicos.rc.biblioteca.unesp.br/index.php/estgeo 
garrafa coletora GA-375) e a menor concentração de Si $(0,0607 \mathrm{mg} / \mathrm{L})$ ocorreu na Estação "C" (Garrafa coletora GC-196) em setembro de 2012, isto é, no final da estação seca (Figura 6C).

\section{DISCUSSÃO DOS RESULTADOS E CONSIDERAÇÕES ACERCA DO COMPORTAMENTO DO NÍVEL FREÁTICO E A MOBILIDADE DOS ELEMENTOS AL, FE E SI NA VERTENTE}

Os dados da mensuração do nível freático na vertente estudada e os índices de precipitação de chuvas no município de Diamantina/MG indicaram que a dinâmica do nível freático na área de estudo esteve dependente da distribuição dos eventos de precipitação ao longo do ano hidrológico de 2011-2012. Desse modo, é possível concluir que a resposta do nível freático à variação dos índices de precipitação foi lenta nas Estações de monitoramento "A" e "B", enquanto, nas Estações "C" e "D", esta resposta foi mais imediata, condicionada, sobretudo, pelo ambiente mal drenado verificado na baixa vertente (Figura 2).

Estes dados sugerem, ainda, que a maior ou menor mobilidade dos elementos $\mathrm{Al}$, $\mathrm{Fe}$ e Si nas águas subsuperficiais da vertente investigada é influenciada pela variação dos índices de precipitação e pela consequente oscilação do nível freático, no período de alternância entre os ciclos de umedecimento e dessecação dos solos, uma vez que os dados de pH não indicaram uma boa correlação com a concentração desses elementos nas águas analisadas.

Rocha (2011) analisou a concentração dos elementos químicos $\mathrm{Al}, \mathrm{Fe}, \mathrm{Si}, \mathrm{Ca}, \mathrm{Mn}$, $\mathrm{Mg}, \mathrm{Na}$ e K nas águas correntes de alguns pontos do rio Jequitinhonha, Ribeirão do Inferno e Rio Pinheiro, situados sobre as litologias da Formação Sopa Brumadinho e Galho do Miguel na Serra do Espinhaço Meridional. As coletas de água foram realizadas por este autor durante os meses de fevereiro de 2008 (estação chuvosa) e agosto de 2008 (estação seca). Os teores de Si encontrados por Rocha (2011) em fevereiro variaram de $0,71 \mathrm{mg} / \mathrm{L}$ a $0,04 \mathrm{mg} / \mathrm{L}$, com média de $0,275 \mathrm{mg} / \mathrm{L}$. No mês de agosto, por sua vez, a concentração deste elemento variou de $3,2 \mathrm{mg} / \mathrm{L}$ a $0,03 \mathrm{mg} / \mathrm{L}$, com média de $0,275 \mathrm{mg} / \mathrm{L}$. Os dados apresentados por Rocha (2011), portanto, sugerem que a maior perda de sílica ocorreu durante a estação seca. Todavia, os dados analisados nas águas subsuperficiais da vertente estudada indicaram que a maior mobilidade deste elemento ocorreu no final da estação chuvosa e início da seca. Isto condiz com as observações realizadas por Lucas (2007), quando afirma que as concentrações de Si dissolvido são mínimas no início da estação chuvosa, mas aumentam progressivamente ao longo da estação chuvosa e na medida em que se eleva o tempo de residência da água no pedoambiente.

De acordo com Bourrié, Trolard e Freytet (2008), a concentração de sílica em equilíbrio com o quartzo é de cerca de $6 \mathrm{mg} / \mathrm{L}$, ou seja, quando a concentração do Si

Número Especial da Revista Estudos Geográficos - XIII Seminário da Pós-Graduação em Geografia, Rio Claro, 15(0): 80-100, jan./jun. 2017 (ISSN 1678-698X) http://www.periodicos.rc.biblioteca.unesp.br/index.php/estgeo 
Funcionamento hídrico e transferência de...

dissolvido é superior a este valor, este elemento deve ser proveniente da dissolução de outros silicatos mais vulneráveis. Kämp, Curi e Marques (2009) afirmam que a solubilidade da sílica amorfa varia entre 50 a $60 \mathrm{mg} / \mathrm{L}$, enquanto que a solubilidade do quartzo aumenta entre 3 a $11 \mathrm{mg} / \mathrm{L}$. Na vertente estudada, os teores de $\mathrm{Si}$ superiores ao limiar de $6 \mathrm{mg} / \mathrm{L}$ devem-se, provavelmente, à dissolução da muscovita $\left(\mathrm{KAl}_{2}\left(\mathrm{Si}_{3} \mathrm{Al}\right) \mathrm{O}_{10}(\mathrm{OH})_{2}\right)$, mineral encontrado na composição estrutural do filito e do quartzito. Entretanto, quando o teor de Si dissolvido é menor que $6 \mathrm{mg} / \mathrm{L}$, há uma indicação de que o quartzo dos solos da vertente começa a ser dissolvido.

Pode-se inferir, dessa forma, que na média e na baixa vertente os baixos teores de Si mensurados nas águas subsuperficiais sugerem que, principalmente na estação seca, quando os teores de Si diminuíram consideravelmente, houve condições propícias para a dissolução do quartzo. Também é possível concluir que parte do silício liberado na solução do solo pode combinar com íons livres de Al e outros cátions solúveis, formando argilominerais, como é 0 caso da caulinita $\left(\mathrm{Al}_{2} \mathrm{Si}_{2} \mathrm{O}_{5}(\mathrm{OH})_{4}\right)$, já a outra parte do $\mathrm{Si}$ deve ser exportada para a rede de drenagem.

Os teores de alumínio mensurados nas águas coletadas da vertente variaram de $0,1584 \mathrm{mg} / \mathrm{L}$ a $0 \mathrm{mg} / \mathrm{L}$, com média de $0,0553 \mathrm{mg} / \mathrm{L}$ durante todo o período de investigação da pesquisa. A maior perda de Al foi verificada no início da estação chuvosa, quando os níveis de precipitação foram mais elevados, porém, no final da estação chuvosa (abril e maio) não se registrou perda desse elemento nas águas coletadas nos pontos de monitoramento. Na estação seca os teores do alumínio não ultrapassaram $0,0438 \mathrm{mg} / \mathrm{L}$. Ao comparar estes dados com os apresentados por Patel-Sorrentino et al. (2007) - os quais variaram de $1,06 \mathrm{mg} / \mathrm{L}$ a $2,02 \mathrm{mg} / \mathrm{L}$ em solos ferralíticos e 1,3 mg/L a 6,3 mg/L em ESPODOSSOLOS da Amazônia Central - com os dados de Rocha (2011), na Serra do Espinhaço Meridional - os quais não ultrapassaram $0,2 \mathrm{mg} / \mathrm{L}$ - pode-se inferir que as perdas de Al verificadas na vertente são baixas. Isto pode ser explicado pelo fato de que os índices de $\mathrm{pH}$ mensurados na vertente não foram nem demasiadamente ácidos nem extremamente básicos, uma vez que o $\mathrm{pH}\left(\mathrm{H}_{2} \mathrm{O}\right)$ dos solos variaram de 4,36 a 5,94 e o pH mensurado nas águas coletadas dos solos variaram entre 4,5 e 7,5. González-Bonorino (1972) afirma que a solubilidade do alumínio é muito baixa em pH entre 4 e 9, portanto, este elemento é pouco solúvel nas condições de $\mathrm{pH}$ observadas na vertente.

Durante o ano hidrológico de 2011-2012 os teores de ferro dissolvidos nas águas subsuperficiais na vertente variaram entre $0,2129 \mathrm{mg} / \mathrm{L}$ e $0,0207 \mathrm{mg} / \mathrm{L}$, com média de $0,0585 \mathrm{mg} / \mathrm{L}$. As maiores concentrações desse elemento foram verificadas nos dias do ano em que se observou a incidência de eventos pluviométricos significativos (superiores a $30 \mathrm{~mm}$ ) após períodos de estiagem. Os teores do Fe nas águas dos solos da vertente foram consideravelmente inferiores àqueles mensurados em águas drenadas de solos ferralíticos $(2,4 \mathrm{mg} / \mathrm{L}$ a $2,8 \mathrm{mg} / \mathrm{L})$ e de ESPODOSSOLOS $(0,45 \mathrm{mg} / \mathrm{L}$ a $0,55 \mathrm{mg} / \mathrm{L})$ obtidos por Patel-Sorrentino et al. (2007). A comparação dos teores mínimos desse elemento na vertente, contudo, foram relativamente próximos aos encontrados por Rocha (2011) - 0,02 mg/L - na bacia do Rio Jequitinhonha na Serra do Espinhaço Meridional.

Número Especial da Revista Estudos Geográficos - XIII Seminário da Pós-Graduação em Geografia, Rio Claro, 15(0): 80-100, jan./jun. 2017 (ISSN 1678-698X) http://www.periodicos.rc.biblioteca.unesp.br/index.php/estgeo 
O Fe é um elemento sensível às condições de oxi-redução, assim, este elemento é mais facilmente mobilizado quando se verifica o rebaixamento do nível freático entre os eventos de maior precipitação pluviométrica, pois a percolação da água gravitacional ao longo dos perfis dos solos aumenta o potencial redox em ambientes fortemente reduzidos (NASCIMENTO et al., 2008). Isso foi observado, por exemplo, nas Estações de monitoramento "C" e "D" no dia 15 de novembro de 2011 (Figura 6B), quando se verificou que, após um período de baixas precipitações (inferiores a $10 \mathrm{~mm}$ diários) e, consequente, rebaixamento do nível freático, a incidência de 84,8 $\mathrm{mm}$ de chuvas determinou imediatamente a elevação do nível freático e a maior mobilidade do ferro em solução nos pontos de monitoramento citados.

Diante do exposto, pode-se afirmar que saída do ferro entre os períodos de maior precipitação foi mais evidente nas Estações de monitoramento "C" e "D". Os materiais que constituem os solos da Estação "D" (TR7), devido às condições de hidromorfia mais rigorosa, são empalidecidos (croma menor que 3), portanto, empobrecidos em ferro. Dessa forma, pode-se supor que os picos elevados da concentração de ferro nas águas do ponto de monitoramento " $D$ " se referem, na verdade, aos teores desse elemento eluviados dos horizontes de alteração da Estação de monitoramento "C" (zona plintítica, ambiente no qual predominam as condições de hidromorfia sazonal) e iluviados na Estação "D" (ambiente em que as condições hidromórficas são mais acentuadas).

Por fim, ressalta-se que os teores de Fe nas águas dos solos da vertente podem ser provenientes tanto do intemperismo dos minerais primários que constituem, sobretudo, o filito da Formação Sopa Brumadinho, quanto da dissolução dos óxidos de ferro (ferrihidrita, magnetita, hematita ou goethita) que já existiam no pedoambiente (zona plintítica, concreções ferruginosas, nódulos ferruginosos).

\section{AGRADECIMENTOS}

Ao CNPq pela concessão da bolsa de estudos à primeira autora durante o mestrado; à FAPESP pelo financiamento do projeto "Diferenciação das paisagens cársticas sobre rochas siliciclásticas na Serra do Espinhaço Meridional - Brasil" (Processo 08/50157-5), coordenado pela professora Dra. Nádia Regina do Nascimento; à professora Dra. Célia Regina Montes, ao técnico Gustavo Galdin do Laboratório de Ecologia Isotrópica - USP/ESALQ pelo auxílio nas análises de ICP-OES; ao Instituto Estadual de Florestas (IEF) e aos gestores do Parque Estadual do Biribiri por todo auxílio nos trabalhos de campo realizados nesta pesquisa.

Número Especial da Revista Estudos Geográficos - XIII Seminário da Pós-Graduação em Geografia, Rio Claro, 15(0): 80-100, jan./jun. 2017 (ISSN 1678—698X) http://www.periodicos.rc.biblioteca.unesp.br/index.php/estgeo 


\title{
REFERÊNCIAS BIBLIOGRÁFICAS
}

\begin{abstract}
ALMEIDA-ABREU, P. A.; RENGER, F. E. Serra do Espinhaço Meridional: um orógeno de colisão do Mesoproterozoico. Revista Brasileira de Geociências, São Paulo, v.32, n.1, 2002.
\end{abstract}

BIGARRELLA, J. J.; BECKER, R. D.; PASSOS, E. Estrutura e origem das paisagens tropicais e subtropicais: intemperismo biológico, pedogênese, laterização, bauxitização e concentração de bens minerais. V. 2. Florianópolis: Editora da Universidade Federal de Santa Catarina, 1994, p. 547-555; 567-612.

BOULET, R. Análise Estrutural da cobertura pedológica e cartografia. CONGRESSO BRASILEIRO DE CIÊNCIAS DO SOLO, 21, 1988, Campinas. Anais do XXI Congresso Brasileiro de Ciências do Solo. Campinas: Sociedade Brasileira de Ciência do Solo, 1988.

BOURRIÉ, G.; TROLARD, F.; FREYTET, P. Alteration chimique. DEWOLF, Y.; BOURRIÉ, G. Les formations superficielles: genèse, typologie, classification, paysages et environnements ressources et risques. Paris: Ellipses, 2008.

DUCHAUFOUR, P. Introduction à la science du sol: sol, végétation, environnement. 6 édition. Paris: DUNOD, 2001. 332 p.

GONZÁLEZ-BONORINO, F. Introduccion a la geoquímica. Washington: OEA, 1972. Vi, 140 p. (Colección de monografías científicas; v. 8)

INSTITUTO NACIONAL DE METEOROLOGIA (INMET). Dados climáticos registrados pela média histórica (1961-1991) na Estação Meteorológica de Diamantina - MG. INMET, 2012.

KÄMP, N.; CURI, N.; MARQUES, J. J. Óxidos de alumínio, silício, manganês e titânio. MELO, V. F.; ALLEONI, L. R. F. Química e mineralogia do solo - Parte 1: Conceitos básicos. Viçosa: Sociedade Brasileira de Ciência do Solo (SBCS), 2009, p. $573-610$.

KING, L. C. A Geomorfologia do Brasil Oriental. Rio de Janeiro: Revista Brasileira de Geografia, v. 18, n. 2, p. 147-265, 1956.

KÖPPEN,W. Climatologia. México: Fundo de Cultura Econômica, 1931. 207 p.

LUCAS, Y. Systémes pédologiques em Amazonic bréssillienne: Équilibre, désequillibres et transformations. 1989. 157 p. Tese (Doutorado) - Universidade de Poitiers, Paris.

Número Especial da Revista Estudos Geográficos - XIII Seminário da Pós-Graduação em Geografia, Rio Claro, 15(0): 80-100, jan./jun. 2017 (ISSN 1678—698X) http://www.periodicos.rc.biblioteca.unesp.br/index.php/estgeo 
LUCAS, Y.. Cycles du silicum, de l'aluminium et du fer. Cap.3. PEDRO, Georges. Cycles biogéochimiques et ecosystems continetaux. Les Ulis (FR): EDP Sciences, Institut de France Académie des sciencies, n.27, 2007, p.76 - 99.

NASCIMENTO, N. R. et al. Podzolization as a deferralitization process: dynames and chemistry of ground and surface waters in an Acrisol - Podzol sequence of the upper Amazon Basin. European Journal of soil sciencie, v. 59, p. 911-924, october. 2008.

NEVE, S. de C.; ABREU, P. Â., FRAGA, L. M. S. Fisiografia. Serra do Espinhaço Meridional: paisagens e ambientes. Belo Horizonte: $O$ Lutador, 2005. p. 47-60.

PATEL-SORRENTINO, N. et al. Fe, Al and Si species and organic matter leached off a ferrallitic and podzolic soil system from Central Amazonia. Geoderma, n. 137, p. $444-454,2007$.

RENGER, F. E.; KANAUER, L. G. Espinhaço-Quo Vadis? (Onde está? - aonde vai): a evolução dos conhecimentos sobre a cordilheira do espinhaço meridional em Minas Gerais entre 1979 e 1995. Geonomos, Belo Horizonte, v.3, n. 1, 31-39, 1995.

ROCHA, L. C. Desnudação geoquímica na evolução da Serra do Espinhaço Meridional - MG - Brasil. Tese (Doutorado em Geografia). 2011. 179f. Instituto de Geociências, Universidade Federal de Minas Gerais, Belo Horizonte, 30 de junho de 2011.

SAADI, A. A geomorfologia da Serra do Espinhaço em Minas Gerais e de suas margens. Belo Horizonte: Geonomos, Belo Horizonte, v.3, n.1, 1995, p.41-63.

SANTOS, R. D., LEMOS, R. C.; SANTOS, H. G.; KER, J. C.; ANJOS, L. H.C. Manual de descrições e coleta de solo no campo. 5 ed. Viçosa: Sociedade Brasileira de Ciência do Solo, 2005. 100p.

SILVA, A. C.; PEDREIRA, L. C. V. S. F.; ABREU, P. A. A. Serra do Espinhaço Meridional: paisagens e ambientes. Belo Horizonte: O Lutador, 2005. 272. p.

SOARES, B. F. Dinâmica dos elementos químicos e os processos de gênese e evolução dos solos de uma vertente do Planalto de Diamantina - Parque Estadual do Biribiri, Diamantina/MG. 2013, 188f. Dissertação (Mestrado em Geografia), Programa de Pós Graduação em Geografia - Tratamento da Informação Espacial, Pontifícia Universidade Católica de Minas Gerais, Belo Horizonte, 27 de setembro de 2013. 